\title{
Hip and groin pain in sub-elite South African footballers
}

\author{
D J Dowson, ${ }^{1} \mathrm{MBBCh} ; \mathbf{H}$ Bayne,${ }^{2} \mathrm{PhD} ; \mathbf{C ~ C ~ G r a n t , ~}{ }^{1} \mathrm{PhD}$ \\ ${ }^{1}$ Section Sports Medicine, University of Pretoria, South Africa \\ ${ }^{2}$ High Performance Centre, University of Pretoria, South Africa
}

Corresponding author: DJ Dowson (donna@drdowson.co.za)

Background. Groin injuries are common in football. This can be attributed to the nature of the sport involving rapid accelerations, decelerations, abrupt directional changes and kicking. Groin injuries require lengthy rehabilitation times and predispose players to further injuries. Previous groin injury is a risk factor for future groin injuries, suggesting players are inadequately rehabilitated or the original cause has not been addressed.

Objectives. To describe the prevalence, nature and treatment patterns of groin injuries in sub-elite players, and to investigate differences in hip strength and range of motion between players with and without a history of groin injury.

Method. Thirty sub-elite, senior university male players were interviewed and questioned regarding groin injuries sustained in the preceding three years. They were assessed using the HAGOS questionnaire, and underwent isokinetic hip flexion/extension strength, adductor squeeze and range of motion tests.

Results. Seventeen players (57\%) reported having a previous groin injury, with an average score of 83 (16) [mean (SD)] on the HAGOS, compared with 92 (5) for non-injured players. Of the previously injured players, $29 \%$ did not seek treatment from a medical professional. Injuries included adductor strain (35\%), inguinal-related (18\%), iliopsoas-related (12\%) and hip joint pathology (6\%). The average time off was 25 days. There were no significant differences in isokinetic hip flexion/extension strength, adductor strength and range of motion.

Conclusion. The prevalence of groin injuries in this population is relatively high (57\%) and requires lengthy rehabilitation time. The HAGOS is a suitable tool to identify groin pain in this population within the sports and recreation and quality of life subscales. Isokinetic hip strength and range of motion testing lacked sensitivity in detecting deficits in players with a previous groin injury. Only two-thirds of injured players consulted a medical practitioner, increasing the likelihood that rehabilitation was inadequate. It is therefore recommended that player/coach education regarding injury management improve in order to reduce subsequent injuries.

Keywords. HAGOS, groin injury, prevalence, range of motion, isokinetic strength

S Afr J Sports Med 2015;27(4):114-117. DOI:10.17159/2078-516X/2015/ v27i4a425

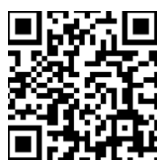

The sport of football involves repetitive changes of direction, rapid acceleration and deceleration, and kicking. These multidirectional and multi-planar movements place substantial load on the hip region.

Hip and groin injuries are common in football, with reported annual incidences of $5-28 \%{ }^{[1]}$ and nearly one-third of all players will experience a groin injury during the course of their careers. $^{[2]}$ In most cases, players return to play after less than four weeks ${ }^{[3]}$ but some injuries persist and can lead to long-standing disability with lengthy absences from sport. ${ }^{[1]}$

The typical groin injury involves one or more anatomical structures in the groin region. Recent consensus ${ }^{[4]}$ describes categorisation of groin injuries based on the involved clinical entities: adductorrelated, iliopsoas-related, inguinal-related, pubic-related and hip-related groin pain. There is acknowledgement that multiple pathologies can coexist in patients with chronic groin pain, with hip joint pathology thought to be a major contributor to secondary breakdown of adjacent structures. ${ }^{[5]}$

The Copenhagen Hip and Groin Outcome Score (HAGOS) is a self-reported questionnaire evaluating hip and groin disability status on a scale from 0 to 100 , where a score of 100 indicates no hip and groin problems and 0 indicates severe problems. ${ }^{[6]}$ The questionnaire consists of six separate subscales for the assessment of the following: Symptoms, Pain, Physical function in Daily Living, Physical function in Sports and Recreation, Participation in Physical Activities, and hip and/or groin-related Quality of Life. Each subscale is scored as a percentage of the total possible score. ${ }^{[6]}$ The HAGOS questionnaire therefore allows for an objective measure of a subjective perception. Thorborg et al. recently evaluated 444 football players, who were hip and groin injury-free to establish reference values for the HAGOS in injury-free male football players. ${ }^{[6]}$ The mean reference ranges for injury-free football players with no pain, including no pain from the previous season, was a score of 100 in all categories except in the symptoms subscale, where the average score was $89 \%{ }^{[6]}$

A number of risk factors for groin injuries in football players have been established. These include a history of previous groin injury, ${ }^{[7]}$ decreased adductor muscle strength, ${ }^{[7,8]}$ decreased hip abduction range of motion, decreased levels of sports specific training, abdominal muscle recruitment, limb length discrepancy and pelvic instability. ${ }^{[7]}$ There is little data in the literature analysing the cause as to why a previous groin injury will predispose a player to another groin injury.

Isokinetic assessment is currently the reference method for measuring dynamic muscle strength. ${ }^{[9]}$ Isokinetic testing has been used to define normative values of hip muscle strength in uninjured football players, not only to identify players at risk but also to aid in return to play decisions following groin injuries. ${ }^{[10]}$ It has been demonstrated that hip range of motion was reduced in football players with current long-standing groin pain. ${ }^{[8]}$ Preliminary work done in a small study group associated hip stiffness with an increased incidence of groin injury. ${ }^{[11]}$

The focus of this study was to describe the prevalence, nature and treatment patterns of groin injuries in sub-elite players, to examine hip and groin disability scores, and to investigate differences in strength and range of motion in players with and without a history of groin injury.

\section{Methods}

Thirty male senior league university football players from within Gauteng, South Africa, were invited to participate in the study. The 
participants train on average five times a week for 90 minutes a session with one to two 90 minute matches a week. Ethical approval was obtained from the Research Ethics Committee, Faculty of Health Sciences of the University of Pretoria and each player gave written consent.

A personal interview was conducted with each player to obtain injury history information, including whether they had ever suffered a groin injury in the previous three years, which medical professional(s) had been consulted after the injury, the diagnosis, and time until return to play. Players also completed the HAGOS Questionnaire. ${ }^{[6]}$ Players with a history of groin injury were allocated to the case group and the remainder to the control group.

Isokinetic hip flexion and extension strength was tested in the supine position with a Biodex ${ }^{\oplus}$ isokinetic dynamometer (Shirley, New York, USA). The protocol consisted of concentric testing of the hip flexors and extensors at $60 \%$ and eccentric testing of the hip flexors at $60 \%$ s. Hip adductor muscle strength was measured using a sphygmomanometer, with the player in a supine position with his knees bent at $90^{\circ}{ }^{\circ}{ }^{[8]}$

Hip extension range of motion was assessed using the Thomas Test; with the player supine at the edge of the plinth and both hips flexed simultaneously to their limit, thus removing lumbar lordosis. Whilst stabilising the non-tested hip firmly in position to maintain pelvic tilt, the limb being tested was lowered over the edge of the plinth and the hip extension angle measured with a goniometer. ${ }^{[12]}$ Hip rotation range of motion was assessed with the player in the prone position with the knee flexed at $90^{\circ}$. The tested limb was rotated internally and externally until resistance was met and measured with a goniometer. ${ }^{[12]}$ The Bent knee fall out (BKFO) test was performed with the player supine and the tested hip flexed to $45^{\circ}$ and the knee flexed to $90^{\circ}$. The knee was allowed to fall laterally and gentle over pressure (DDI) applied to make sure the participant was relaxed at the limit of movement. The distance between the plinth and the lateral surface of the knee at the level of the fibula head was measured. ${ }^{\left[{ }^{[8}\right.}$

Data from the case group's injured side were compared against the dominant leg of the control group. Data analysis consisted of descriptive statistics to summarise the data and independent samples $\mathrm{t}$-tests. Statistical significance was accepted at $\mathrm{p}<0.05$.

\section{Results}

Seventeen players (57\%) reported having experienced a previous groin injury within the last three years of play. Of these, six (35\%) had sustained an adductor-related injury, three (18\%) sustained an inguinal-related injury, two (12\%) sustained an iliopsoas-related injury, two (12\%) involved the hip joint, and four (23\%) were unspecified. Three players (18\%) reported having experienced multiple groin injuries. The average time before return to play was 25 days, with ranges from three days to four months. A total of $30 \%$ of players had severe injuries ( $>28$ days), $30 \%$ had moderate injuries (7-28 days) and $40 \%$ had mild injuries ( $<7$ days). Eleven (65\%) of the injured players sought treatment from a physiotherapist for their injuries, five (29\%) did not have any treatment and only one (6\%) consulted a sports physician.

There were no statistically significant differences between the case and control groups for age, height or mass (Table 1), nor for any of the range of motion or strength variables assessed (Figure 1). Previously injured players reported significantly lower HAGOS scores in the
Sports and Recreation subscale (case 80.1 (18.1); control 92.6 (6.4); $\mathrm{t}=2.560 ; \mathrm{p}=0.019)$ and Quality of Life subscale (case 75.3 (15.5); control 87.7 (13.1); $\mathrm{t}=2.281 ; \mathrm{p}=0.031$ ) (Figure 2).

Table 1. Comparison of descriptive values, previously injured versus control group

\begin{tabular}{lcccccccc}
\hline & \multicolumn{2}{c}{ Case } & & \multicolumn{2}{c}{ Control } & & \\
\cline { 2 - 3 } & Mean & SD & & Mean & SD & & t & p \\
\hline Age (years) & 21.6 & 1.5 & & 21.1 & 1.9 & -.806 & .427 \\
Height $(\mathrm{cm})$ & 175.8 & 12.5 & & 174.0 & 5.4 & -.485 & .631 \\
Mass (kg) & 69.7 & 8.0 & & 66.3 & 6.6 & -1.244 & .224
\end{tabular}
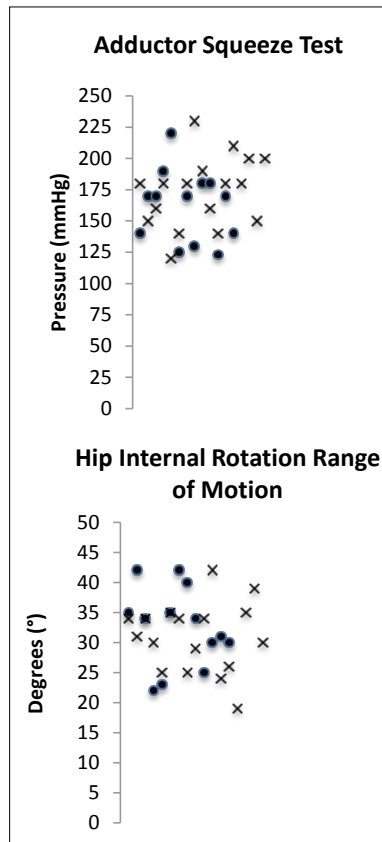

Bent Knee Fall Out

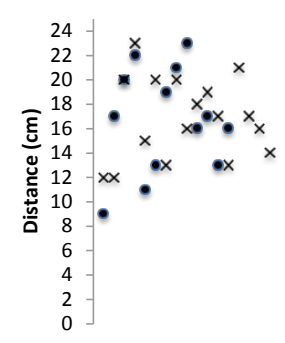

Hip Extension Peak Torque

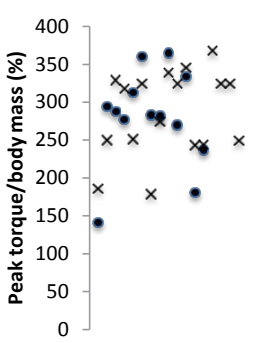

Thomas Test
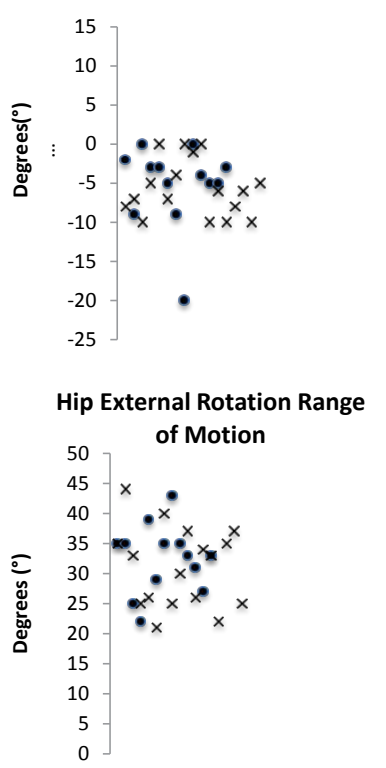

Hip Flexion Peak Torque

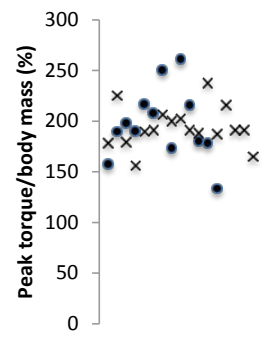

Eccentric Hip Flexion Peak Torque
Fig. 1. Range of motion and strength results for case group (previously injured) and control group Case group: $\times$ Control Group: •

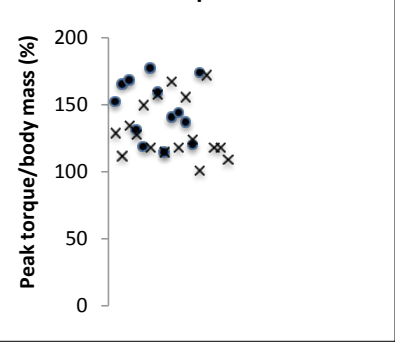

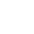




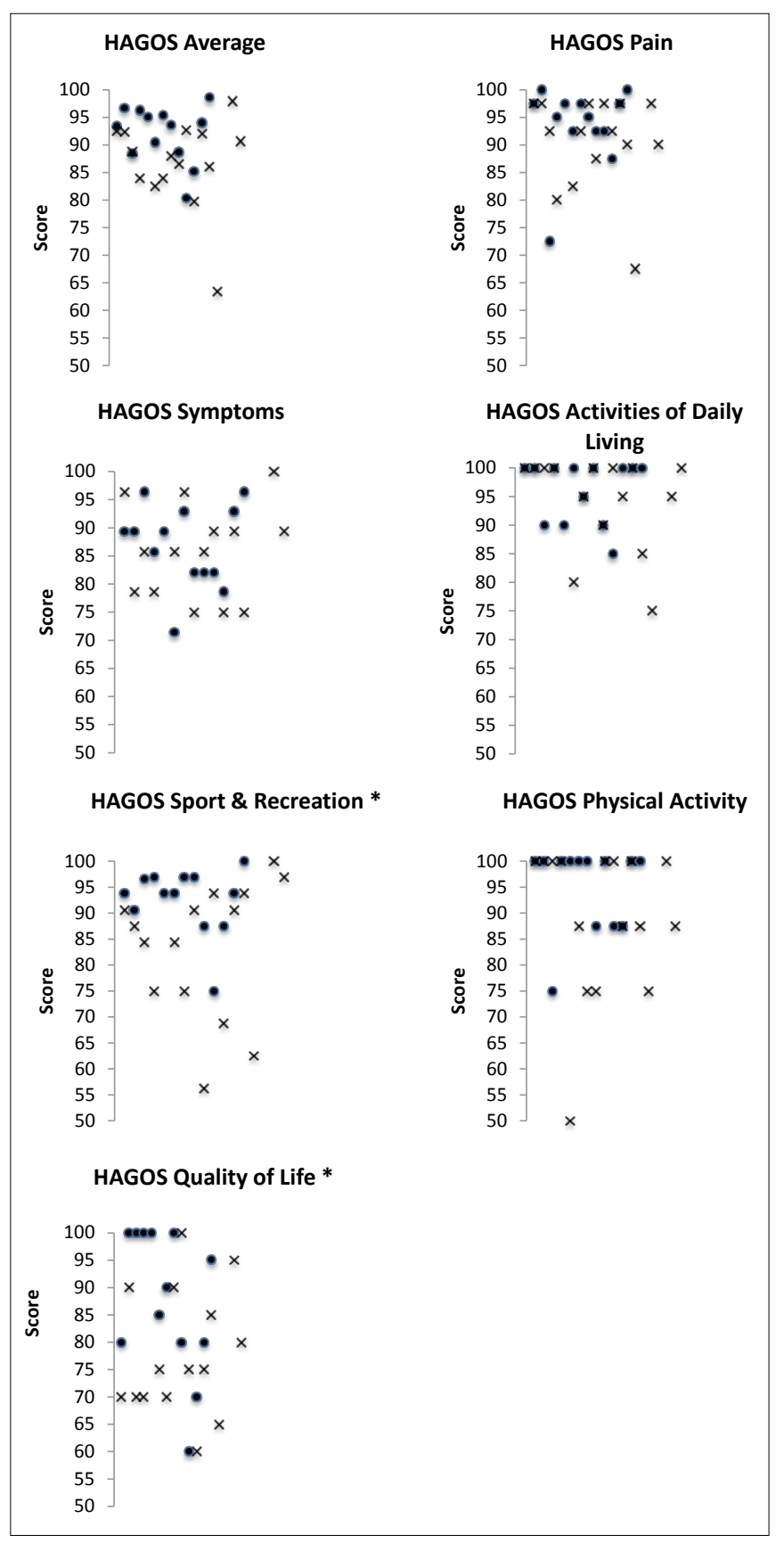

Fig. 2. HAGOS values for case group (previously injured) and control group Case group: $\times$ Control Group: $\bullet$

* Significantly different from control, $p<0.05]$

\section{Discussion}

The findings of this study confirmed the HAGOS as a responsive measure of hip and groin disability outcome and injury status in this population, specifically in the Sports and Recreation and Quality of Life subscales. HAGOS is the only patient reported outcome questionnaire aimed at young to middle-aged adults presenting with groin pain ${ }^{[14]}$ and it has been proven to be valid, reliable and responsive for evaluating individuals with hip and/or groin pain, including male soccer players. ${ }^{[6]}$ The HAGOS is designed to identify current symptoms, and this research suggests that previously injured players do still suffer from persistent subjective symptoms that affect the players defined Sports and Recreation and Quality of Life subscales.

It has been suggested that one in three football players will experience a groin injury during their careers. ${ }^{[2]}$ The incidence reported in this study was substantially higher than this figure, with $57 \%$ of players having suffered from a groin injury in their careers thus far. This may be due, in part, to the subjective nature of injury history recall that was relied upon in the current study. Nevertheless, the HAGOS results substantiate the players' recall of a previous groin injury.

Adductor-related injury was the most common diagnosis. This is comparable to similar studies that suggest adductor-related injuries account for between $51 \%^{[16]}$ and $64 \%^{[1]}$ of groin injuries.

An important concern identified in this study is that almost a third of players (29\%) did not seek medical attention for their injuries. Their general view was that 'rest and stretches' would be adequate. Yet the time off from play was significant, with an average of 25 days. Vague symptoms and an insidious onset of groin pain allows players to train and play with pain, which may result in the player delaying seeking immediate medical attention, thus often leading to a chronic presentation. ${ }^{[13]}$ Hölmich and Thorborg categorised mild groin injuries as 4-7 days injury time, moderate groin injuries as 8-28 days injury time and more than 28 days as severe. ${ }^{[16]}$ In this study $30 \%$ of players had severe injuries, $30 \%$ had moderate injuries and $40 \%$ had mild injuries. This is comparable to a large study involving 907 sub-elite football players of which $43 \%$ sustained moderate injuries and $33 \%$ sustained severe injuries. ${ }^{[16]}$

Previous research has identified significant differences in hip adductor strength and range of motion between uninjured footballers and symptomatic players with long-standing groin pain. ${ }^{[8]}$ In the current study, players with a history of groin injury were asymptomatic at the time of testing, which may explain why these findings do not replicate this result. The adductor squeeze values were lower than those reported in previous research in Gaelic football players, where the control group attained adductor squeeze strength values of $269.3 \pm 25.4 \mathrm{mmHg}$, and the injured group attained values of $202.9 \pm 36.7 \mathrm{mmHg} .{ }^{[8]}$ Another study recorded values of $209 \mathrm{mmHg} \pm 42.3$ in groin pain free elite football players compared to $180.5 \pm 30.2$ in players with groin pain. ${ }^{[15]}$ Allowing for measurement error and variation, it has been suggested that a threshold of $200 \mathrm{mmHg}$ may be useful clinically. ${ }^{[13]}$

Limitations of this study include the small sample size and subjective nature of patient injury history recall, which may have influenced the validity of the clinical entity diagnosis reported. However, the injury data obtained from the players agrees with the typical distribution of clinical presentation of groin injury.

\section{Conclusion}

Groin injuries are more common in sub-elite South African footballers than has been reported in previous literature on footballrelated injury. The HAGOS is a suitable tool to identify groin pain in this population within the Sports and Recreation and Quality of Life subscales. Isokinetic hip strength and range of motion testing lacked sensitivity in detecting deficits in players with a previous groin injury. A new and important finding was that almost a third (29\%) of players did not seek treatment from a qualified professional, and 
only $6 \%$ of players consulted a sports physician. This represents suboptimal injury management.

The study concludes that player and coach education on appropriate injury management strategies is necessary. This should include guidance on injury prevention interventions, and the proper pathways to follow for treatment and rehabilitation of injuries.

\section{References}

1. Werner J. UEFA injury study: a prospective study of hip and groin injuries in professional football over seven consecutive seasons. Br J Sports Med 2009;43(13): 1036-1040. [http://dx.doi.org/10.1136/bjsm.2009.066944]

2. Kinchington M. Groin pain: a view from below; the impact of lower extremity function and podiatric interventions. Aspetar Sports Med J 2013;2(3):360-368.

3. Ekstrand J, Hägglund $M$, Walden $M$. Epidemiology of muscle injuries in professional football (soccer). Am J Sports Med 2011;399(6):1266. [http://dx.doi org/10.1177/0363546510395879]

4. Weir A, Brukner P, Delahunt E, et al. Doha agreement meeting on terminology and definitions in groin pain in athletes. Br J Sports Med 2015;49(12):1-8. [http://dx.doi org/10.1136/bjsports-2015-094869]

5. Rankin A, Bleakley C, Cullen M. Hip joint pathology as a leading cause of groin pain in the sporting population. Am J Sports Med 2015;43(7):1698-1703 [http://dx.doi. org/10.1177/0363546515582031]

6. Thorborg K, Branci S, Stensbirk F, et al. Copenhagen hip and groin outcome score (HAGOS) in male soccer: reference values for hip and groin injury-free players. $\mathrm{Br}$ Sports Med 2014;48(7):557-559. [http://dx.doi.org/10.1136/bjsports-2013-092607]
7. Garvey JFW, Read JW, Turner A. Sportsman hernia: what can we do? Hernia 2010;14(1):17-25. [http://dx.doi.org/10.1007/s10029-009-0611-1]

8. Nevin F, Delahunt E. Adductor squeeze test values and hip joint range of motion in Gaelic football athletes with longstanding groin pain. J Sci Med Sport 2014;17(2): 155-159. [http://dx.doi.org/10.1016/j.sams.2013.04.008

9. Julia M, Dupeyron A, Laffont I, et al. Reproducibility of isokinetic peak torque assessments of the hip flexor and extensor muscles. Ann Phys Rehabil Med 2010;53(5):293-305. [http://dx.doi.org/10.1015/j.rehab/2010.95.002]

10. Hanna CM, Fulcher ML, Elley CR, Moyes SA. Normative values of hip strength in adult male association football players assessed by handheld dynamometry. J Sci Med Sport 2010;13(3):299-303. [http://dx.doi.org/10.1016/j.sams.2008.11.007]

11. Verrall G, Slavotinek J, Barnes P, Esterman A, Oakeshott R, Spriggins A. Hip joint range of motion restriction precedes athletic chronic groin injury. J Sci Med Sport 2007;10(6):463-466. [http://dx.doi.org/10.1016/j.sams.2006.11.006]

12. Appley AG, Solomon L. Concise System of Orthopaedics and Fractures. 2nd Ed. Arnold;2001:174-177.

13. Brukner P, Khan K. Brukner \& Khan's Clinical Sports Medicine. 4th Ed. Australia McGraw-Hill Education;2013:558-568.

14. Thorborg K, Tijssen M, Habets B, Bartels E, Roos E, Hölmich P, et al. PatientReported Outcome (PRO) questionnaires for young to middle-aged adults with hip and groin disability: a systematic review of the clinimetric evidence. Br J Sports Med 2015;49(12):1-11. [http://dx.doi.org/10.1136/bjsports-2014-094224]

15. Malliaras P, Hogan A, Nawrocki A, Crossley K, Schache A. Hip flexibility and strength measures: reliability and association with athletic groin pain. $\mathrm{Br} J$ Sports Med 2009;43(10):739-744. [http://dx.doi.org/10.1136/bjsm.2008.055749]

16. Hölmich P, Thorborg K, Dehlendorff C, et al. Incidence and clinical presentation of groin injuries in sub-elite male soccer. Br J Sports Med 2014;48:1245-1250. [http:// dx.doi.org/10.1136/bjsports-2013-092627] 